\title{
Cigarette use among male and female grade 8-10 students of different ethnicity in South African schools
}

\author{
D Swart, P Reddy, R A C Ruiter, H de Vries
}

Tobacco Control 2003;12:el (http://www.tobaccocontrol.com/cgi/content/full/12/1/e1)

See end of article for authors' affiliations

.....................

Correspondence to:

Dehran Swart, National

Health Promotion Research

and Development Group

Medical Research Council

of South Africa, PO Box

19070, Tygerberg, 7505

Cape Town, South Africa;

dehran.swart@mrc.ac.za

Received

2 December 2002

Accepted

17 December 2002 ide data on the prevalence of cigarette use by male and female South African stu-

Objectives: To provide data on the prevalence of cigarette use by male and female South African stu-
dents of different ethnic backgrounds in grades $8-10$ (ages $\leqslant 11$ to $\geqslant 17$ years), their age of initiation of cigarette use, as well as their access to cigarettes through underage sales.

Design: A nationally representative survey was conducted using self administered questionnaires translated into seven languages.

Setting: School based.

Participants: Students in grades 8-10 in all of South Africa's nine provinces.

Outcome measures: The prevalence data for current users of cigarettes (smoked on one or more days in 30 days preceding the survey), and for the age of initiation (first smoking cigarettes before the age of 10 ) were analysed.

Results: Of the 160 selected schools, 123 schools participated in the survey. The completed survey comprised 6045 of 7074 selected students; $23 \%$ of the sample reported being current users of cigarettes. Significantly more males $(28.8 \%)$ than females (17.5\%), and significantly more "Coloured" students than "Black/African" students were classified as current smokers. Sex was the strongest contributor to the prediction of current smoking status. On the issue of age of initiation, $18.5 \%$ of students reported having first smoked cigarettes before the age of 10 years with more "Black/African" students than "Coloured" having done so.

Conclusions: In order to tailor tobacco control programmes to the needs of students, historical "racial"/ethnic and sex differences have to be taken into account. Specific determinant studies are needed to understand these differences and to develop appropriate responses.
$\mathrm{T}$ obacco currently accounts for a global burden of over four million deaths each year, a figure projected to rise to about 10 million deaths per year by $2030 .{ }^{1}$ By that date, $70 \%$ of those deaths will occur in developing countries. ${ }^{2}$ Despite this, tobacco use is considered to be one of the chief preventable causes of death in the world. ${ }^{3}$ The majority of adult smokers in developed countries initiate the use of tobacco before the age of 18 , during their adolescent years. ${ }^{45}$ Recent international trends show that the smoking prevalence rates among adolescents is rising, ${ }^{4-7}$ and that the age of initiation is decreasing. ${ }^{458}$ If these patterns continue, tobacco use will result in the death of 250 million children and young people alive today, many of them in developing countries. ${ }^{10}$

Reddy and associates, in studies conducted in 1995 and in 1996, showed that $34 \%$ of adult South Africans, or a total of seven million adults, smoke at least one cigarette a day. ${ }^{11}{ }^{12}$ Meyer-Weitz et al $^{13}$ reported that the smoking prevalence rate for adults dropped to $25 \%$ in 1998 . This corresponds with the smoking rate of $24 \%$ obtained from the most recent national household survey in South Africa, the South African Demographic and Health Survey (SADHS) conducted in 1997. ${ }^{14}$ This reduction might have been caused by the steady increase in tobacco taxes since 1993, and the introduction of health warnings in 1996.

*During the apartheid years, all South Africans were classified in accordance with the Population Registration Act of 1950 into "racial groups"-that is, "Black/African", "Coloured", "White" or "Indian" and the provision of services occurred along these racially segregated lines. The disproportionate provision of services to different "race groups" led to inequities. Information is still collected along these "racial" divisions in order to redress these inequities. In no way do the authors subscribe to this classification.
In contrast to the information on adult smoking behaviour, there is a dearth of knowledge on the smoking behaviour of adolescents in South Africa. From February 1995 to October 1996, smoking prevalence in the 18-24 year age group increased from $31 \%$ to $36 \%$. The inference can be made that most of the members in this 18-24 year age group became regular smokers during their adolescent years. ${ }^{13}$ According to the SADHS, the prevalence of smoking in the 15-19 year age group was $10 \%{ }^{14}$ A literature review conducted on children and tobacco in Southern Africa, ${ }^{15}$ however, argued that it is difficult to obtain an overall impression of smoking prevalence in adolescents. This is due to studies lacking nationally representative samples, differing sample sizes and methodologies being employed, and certain studies being confined to small geographical areas or "racial" groups.*

This article presents findings of the first national tobacco survey among school based adolescents conducted in South Africa. The survey, conducted during 1999, was part of the Global Youth Tobacco Survey (GYTS), a multi-country project that focuses primarily on adolescents aged 13-15 years. The main goal of this article is to report on the prevalence of cigarette smoking, age at initiation of cigarette use, and access to cigarettes via underage sales, with specific attention being paid to the roles of sex and "race". The findings of this study are important as they may provide arguments for future interventions to prevent smoking onset in adolescents in line with the recent Tobacco Products Control Amendment $\mathrm{Act}^{16}$ and supporting regulations ${ }^{17}$ that have been implemented in 2001.

Abbreviations: GYTS, Global Youth Tobacco Survey; HPS, Health Promoting School; SADHS, South African Demographic and Health Survey 
Primarily, this Act bans all advertising and promotion of tobacco products including sponsorship and the free distribution of tobacco products, it restricts smoking in public places including the workplace and public transport, it stipulates penalties for transgressors of the law, and it declares the maximum permissible levels of tar and nicotine. This legislation makes specific mention of preventing youth from becoming addicted to tobacco and restricting the sales of tobacco products to those under 16 years. Regulations make it possible for fines of R10000 (approximately US\$1000) to be imposed on anyone who sells tobacco products to those under 16 years.

\section{METHOD}

\section{Sampling}

A two stage cluster sample design was used to obtain a nationally representative sample of students in grades 8,9 , and 10 ( $\leqslant 11$ to $\geqslant 17$ years). The first stage sampling frame consisted of all public schools containing any of grades 8,9 , and 10. Schools were selected with a probability proportional to the school enrolment size-that is, larger schools had a greater chance of being selected. The second sampling stage consisted of systematic equal probability sampling (with a random start) of classes from each school that participated in the survey. All grade 8, 9, and 10 classes in the selected schools were included in the sampling frame. All students in the selected classes were eligible to participate in the survey.

\section{Questionnaire development}

The South African version of the questionnaire consisted of 93 questions. The questionnaire included 54 core questions, developed by the World Health Organization and the Centers for Disease Control, ${ }^{18}$ and 39 additional questions in order to take into account local tobacco using behaviour and the psychosocial, cultural, and contextual determinants thereof. The questionnaire was translated into six languages. In order to ensure face validity, the questions were pre-tested in the various languages and adapted accordingly. During the pilot phase, students required 20-60 minutes to complete the questionnaire

\section{Training and data collection}

Before data collection could take place, extensive networking occurred with the various stakeholders in the Departments of Health and Education to obtain their endorsement and support for the project. It was agreed to link the GYTS to the Health Promoting Schools (HPSs) initiative, using tobacco control as an entry point for HPSs (schools that have health promotion as a central goal for all their activities). This facilitated the participation of staff from the Provincial Health Promotion Departments as survey administrators.

Training workshops with survey administrators were held over a two week period in all nine provinces. Each survey administrator was assigned one, two or three schools depending on whether the selected school was located in their area of responsibility. Parents and students were issued with information sheets explaining the study in detail, making specific mention of confidentiality and anonymity. Parents were asked to indicate their child's participation by returning consent forms to the school principal. Questionnaires were only issued to those students who consented to participating and whose parents sanctioned their participation. The privacy, confidentiality, and anonymity of students were assured before they started answering the questionnaire. Once completed, the answer sheets were checked and enrolment data were reconciled with the number of questionnaires issued. The answer sheets were scanned in order to capture the data.

\section{Outcome measures}

Current use of cigarettes is defined as having smoked cigarettes on one or more days during the 30 days preceding the survey. ${ }^{4}$ Participants were asked to indicate on how many days they smoked during the past 30 days (one month) with the following possible answers: "0 days", "1 or 2 days", "3 to 5 days", "6 to 9 days", "10 to 19 days", "20 to 29 days", and "all 30 days". For age of initiation, participants were asked how old they were when they tried their first cigarette. The following possible answers were given: "I have never smoked cigarettes", "7 years old or younger", "8 or 9 years old", "10 or 11 years old", "12 or 13 years old", "14 or 15 years old", and "16 years old or older". On the question of access to cigarettes, participants were asked if anyone ever refused to sell cigarettes to them because of their age. Possible answers for this question were: "I did not try to buy cigarettes during the past 30 days (one month)", "Yes, someone refused to sell me cigarettes because of my age", and "No, my age did not keep me from buying cigarettes."

\section{Analysis}

A weighting factor was applied to each student record to adjust for non-response and for the varying probabilities of selection for grade and sex. Epi Info and SUDAAN, a software package for statistical analysis of correlated data, were used to compute prevalence rates and 95\% confidence intervals (CIs) for the estimates. Differences between prevalence estimates were considered significant if the $95 \%$ CIs did not overlap ${ }^{19}$. Analyses of variance and post-hoc Tukey HSD comparisons were used to check for differences on average age between sex and race groups.

\section{RESULTS}

Study sample size and response rates

One hundred and twenty three schools out of the 160 selected schools participated in the survey. Out of 7074 selected students, 6045 participated. The school response rate was $76.9 \%$, the student response rate was $85.5 \%$, and the national overall response rate was $65.7 \%$.

\section{Background characteristics of students}

The sample consisted of $52.6 \%$ females and $47.4 \%$ males (table $1) ; 42.9 \%$ of the sample were aged 13-15 years old, while $47.6 \%$ of the sample were 16 years old and older. Males were slightly older (mean (SD) 15.16 (1.79) years) than females $(14.98$ (1.61) years, $F(1,5618)=16.23, p<0.001)$. The majority of the students were "Black/African" (53.8\%), followed by "White" (14.0\%), "Coloured" (10.9\%), and "Indian" (3.4\%); $16.5 \%$ of the students were not able to classify themselves in one of the historical "race" categories used in South Africa. The average age for "Coloureds" (14.77 (1.63) years) was lower than that for "Black/Africans" ( 15.13 (1.85) years, $\mathrm{p}<0.001$ (Tukey HSD)). The average age for "Indian" students (14.09 (1.94) years) was lower than that for "Black/ African", "Coloured", and "White" students (14.94 (1.23) years, $\mathrm{p}<0.001$ ).

\section{Prevalence of cigarette using behaviour and access to} cigarettes (underage sales)

Table 2 presents the overall percentages for sex and "race" on current use of cigarettes and initiation of cigarette use before the age of 10 years. The overall current smoking rate in the sample was $23 \%$, with males $(28.8 \%)$ smoking more than females $(17.5 \%)$. The "Coloured" smoking rate was the highest, significantly more than that of the "Black/Africans" and "Indians".

The proportion of students that tried their first cigarette before the age of 10 years was $18.5 \%$. No difference was found between the proportions of males and females on this variable. Despite the higher rate of current smokers in the "Coloured" group, more "Black/African" students smoked their first cigarettes before the age of 10 years. 


\begin{tabular}{|c|c|c|c|}
\hline & & $\mathrm{n}$ & $\%$ \\
\hline \multicolumn{4}{|l|}{ Sex* } \\
\hline & Male & 2859 & 47.4 \\
\hline & Female & 2924 & 52.6 \\
\hline \multicolumn{4}{|c|}{ Grade $†$} \\
\hline & 8 & 2533 & 37.6 \\
\hline & 9 & 1654 & 32.4 \\
\hline & 10 & 1620 & 30 \\
\hline \multicolumn{4}{|c|}{ Ageł } \\
\hline & 11 years or younger & 341 & 5.9 \\
\hline & 12 & 230 & 3.7 \\
\hline & 13 & 456 & 8 \\
\hline & 14 & 964 & 15 \\
\hline & 15 & 1159 & 19.9 \\
\hline & 16 & 1154 & 19.1 \\
\hline & $17+$ & 1465 & 28.5 \\
\hline \multicolumn{4}{|c|}{ Race§ } \\
\hline & Black/African & 3155 & 53.8 \\
\hline & Coloured & 860 & 10.9 \\
\hline & Indian & 152 & 3.4 \\
\hline & White & 768 & 14 \\
\hline & Other & 85 & 1.4 \\
\hline & I do not know & 807 & 16.5 \\
\hline
\end{tabular}

*262 participants with missing/invalid data for question on sex. †238 participants with missing/invalid data for question on grade. $\$ 276$ participants with missing/invalid data for question on age. $\S 218$ participants with missing/invalid data for question on "race".

The majority of current smokers under the age of 16 were able to buy cigarettes in a store $(74.2 \%, 95 \%$ CI $64.6 \%$ to $83.8 \%)$. No difference was found on this variable between males and females $(74.2 \%, 95 \%$ CI $61.8 \%$ to $86.6 \%$, and $75.6 \%$, $95 \%$ CI $62.9 \%$ to $88.3 \%$, respectively). It was not possible to report on "racial" differences as the numbers were too small.

The role of sex within the different "race" groups was studied for three of the four "race" groups and on two of three dependent variables. The group of "Indian" students was excluded from these analyses because of the low sample size of this group. Table 2 shows that sex differences were only found on the prevalence of current smoking among "Black/ African" students. In this group, more male students reported that they had smoked in the past 30 days than female students. In the other two "race" groups the percentages between females and males did not differ significantly on cur- rent smoking status. There is a tendency towards "White" females smoking more than "White" males. Furthermore, no reliable differences were found between the proportions of males and females who tried their first cigarette before the age of 10 years within the different "race" groups. With regard to access to cigarettes below the age of 16 years, sample sizes were too small to report any reliable figures.

\section{DISCUSSION}

The multi-country GYTS targeted adolescents with an age range of 13-15 years. In South Africa, this age range ought to correspond to grade $8-10$ students. However, only $42.9 \%$ of the sample fell within this age range and in fact $47.6 \%$ of the students were 16 years or older. This can be accounted for by the legacy of years of apartheid education that was characterised by a lack of schools, limited access to schools, as well as late entry and re-entry into the education system. It is noteworthy that significant percentages of students (16.5\%) did not know where to place themselves within the historical "race" categorisation used in South Africa. Possible reasons may include lack of understanding of the question, reluctance to place themselves into racial categories or they were unaware of the racial categorisation system that was used in South Africa, or a combination of these reasons.

Twenty three per cent of grade 8-10 students nationally smoked cigarettes on one or more days in the past 30 days preceding the survey. In other words, almost a quarter of grade 8-10 students were current users of cigarettes. This figure among adolescents closely parallels the $24 \%$ smoking rate of adults as reported by the SADHS. ${ }^{14}$ The fact that South African adolescents and adults are smoking at similar rates points towards a growing tobacco epidemic among the younger generations of the South African population. This correlates with the extensive and glamorous tobacco advertising and sponsorship that occurred in developing countries, like South Africa, over the past 10 years. ${ }^{20}$ Considering the financial implications of tobacco related morbidity and mortality, and that most tobacco related illnesses affect tobacco users when they are economically productive, ${ }^{21}$ South Africa would do well to prevent its youth from becoming adult smokers. The South African Tobacco Products Control Amendment $\mathrm{Act}^{16}$ of 1999, with one of its fundamental pillars aimed at protecting the youth, provides an excellent point of departure.

\begin{tabular}{|c|c|c|c|c|c|}
\hline & & \multicolumn{2}{|c|}{ Current use* of cigarettes (\%) } & \multicolumn{2}{|c|}{$\begin{array}{l}\text { First smoked cigarettes before the ages of } \\
10 \text { years }(\%) \dagger\end{array}$} \\
\hline & & Prevalence $(95 \% \mathrm{Cl})$ & Total (n) & Prevalence $(95 \% \mathrm{Cl})$ & Total (n) \\
\hline \multicolumn{6}{|l|}{ South Africa } \\
\hline & Male & 28.8 (24.5 to 33.1$)$ & 2488 & $18.9(16.6$ to 21.2$)$ & 1096 \\
\hline & Female & 17.5 (13.1 to 21.9 ) & 2640 & 17.7 (13.0 to 22.4$)$ & 817 \\
\hline & Total & 23.0 (19.0 to 27.0 ) & 5319 & 18.5 (16.6 to 20.4 ) & 1995 \\
\hline \multicolumn{6}{|l|}{ "Race" } \\
\hline \multirow{3}{*}{ Black/African } & Male & 27.1 (21.1 to 33.2 ) & 1336 & 19.7 (15.5 to 24.0 ) & 471 \\
\hline & Female & 10.5 (5.4 to 15.6$)$ & 1375 & 19.5 (16.0 to 22.9 ) & 228 \\
\hline & Total & 18.4 (13.1 to 23.7$)$ & 2788 & 20.0 (16.9 to 23.1$)$ & 716 \\
\hline \multirow[t]{3}{*}{ Coloured } & Male & 37.3 (33.0 to 41.6$)$ & 368 & 12.7 (10.0 to 15.4 ) & 236 \\
\hline & Female & 35.9 (30.1 to 41.6$)$ & 371 & $15.2(11.9$ to 18.4$)$ & 240 \\
\hline & Total & 37.4 (33.8 to 41.0 ) & 762 & $14.2(12.2$ to 23.1$)$ & 492 \\
\hline \multirow[t]{3}{*}{ White } & Male & 25.9 (20.5 to 31.3 ) & 333 & 22.3 (19.0 to 25.5 ) & 195 \\
\hline & Female & 32.9 (27.5 to 38.4$)$ & 362 & $23.8(17.0$ to 30.6$)$ & 194 \\
\hline & Total & 29.0 (22.5 to 35.6$)$ & 708 & 22.7 (18.1 to 27.3$)$ & 395 \\
\hline
\end{tabular}

* Smoked cigarettes on one or more days of the 30 days preceding the survey.

†Among ever smokers.

$\mathrm{Cl}$, confidence interval.

The prevalence of "Indian" and "Other" race groups are not reported here because of small numbers of smokers, especially among females. 
"Coloured" students displayed the highest prevalence of current cigarette use, significantly greater than that of "Black/ African" students. This trend mirrors the results obtained from previous adults surveys which showed higher prevalence for "Coloured" adults as compared to the lower prevalence for "Black/African" adults. ${ }^{11-14}$ Although significantly more males than females are current users of cigarettes, almost equal percentages smoked their first cigarette before the age of 10 years. $^{5}$ This implies that South African females are following the worldwide trend of increasing smoking rates among the female population..$^{22}$ This study shows that "Coloured" females are smoking just as often as "Coloured" males and there is a tendency towards "White" females smoking more often than "White" males.

Almost one fifth of the sample nationally has tried their first cigarette before the age of 10 years. The lower percentage of "Coloured" students that indicated having smoked their first cigarettes before the age of 10 seems to suggest that they started smoking later than the other "race" groups. More "Black/African" students smoked their first cigarettes before the age of 10 when compared to "Coloured" students. This points towards a potential increase in prevalence of cigarette use among "Black/African" adolescents in the near future. Additionally, significantly more "Black/African" males are current smokers than "Black/African" females, but there is no difference with respect to age of initiation. This means that a focused prevention approach is needed for the "Black/ African" community.

The current tobacco legislation bans the sale of cigarettes to minors (under the age of 16 years) ${ }^{16}{ }^{17}$ Almost three quarters of current smokers under 16 were not refused the purchase of cigarettes in a store because of their age. These findings indicate one of two possibilities: that retailers are not aware of the legislation, or that they are aware of it but fail to implement the legislation. Several years have passed since underage sales were banned yet this law has not been successfully implemented and enforced. Only one shopkeeper has successfully been prosecuted for selling tobacco products to those under 16 years. In light of the enactment of more comprehensive legislation, there is an urgent need to create awareness of the law and its regulations, ${ }^{23}$ to increase the fines for those who transgress, to find suitable mechanisms to enforce the law, and ensure that transgressors of the law are prosecuted. This implies that a more comprehensive approach, addressing both individual and environmental determinants, is necessary to limit underage tobacco sales.

\section{Conclusion}

Adolescent specific tobacco control interventions are necessary to avert the potential escalation in tobacco related health care costs and especially to protect the health of the future workforce of South Africa. The results suggest that smoking among male and female adolescents needs to be addressed. These results also imply that female smoking rates in South Africa, as in the international arena, can be expected to increase in the future, necessitating concerted efforts to prevent this international trend from flourishing in this country. Special attention has to be paid to keeping the female smoking rates low, especially among "Black/African" students, as the prevalence of current smoking among "Black/ African" female students is significantly lower than that for "Black/African" male students. Smoking among male and female "Coloured" students also needs to be tackled urgently.

The data highlight the high percentage of young people in South Africa who start smoking cigarettes before the age of 10 years. Tobacco control health education and promotion interventions for youth therefore need to be developed and implemented. Tobacco related issues need to be introduced into the formal school curriculum at an early age, possibly at school inception, and it needs to continue throughout the schooling career.

\section{What this paper adds}

Previous studies on the prevalence of cigarette smoking in South Africa focused primarily on adults. Studies on youth have targeted certain geographical areas and "race" groups. The latest national household survey quoted the smoking rate for those 15-19 years old as 10\%.

This is the first nationally representative study focusing specifically on tobacco use by grade 8-10 school aged children in South Africa. Significantly more males than females and significantly more "Coloured" students than "Black/African" students were classified as current smokers. Sex was the strongest contributor to the prediction of current smoking status. More "Black/ African" students than "Coloured" school children first smoked cigarettes before the age of 10 years.

The level of underage sales of cigarettes is unacceptably high. A combination of strategies is required to enforce the ban of underage sales-that is, create awareness of the regulations and the rationale that underpins them; lobby the community and suitable agencies to enforce the tenets of the law; and prosecute transgressors of the law.

In order to obtain a more comprehensive picture of tobacco using behaviour and related determinants among youth, this school based survey needs to be expanded to youth who are outside of the school environment-for example, those who are homeless or in correctional facilities.

Finally, carefully designed studies must provide an insight into the determinants of tobacco using behaviour that place young people and school aged children at risk. While the sample was not stratified by "race", the results indicate significant differences along historical "racial lines". Although the study is representative of the country at large, in order to tailor programmes to the needs of the various provinces and "race" groups, provincial and "racial" specific determinant studies are needed. These studies should analyse whether determinants for smoking onset may differ within the various groups and cultures in South Africa. These data can then be used to develop scientifically sound interventions tailored to the characteristics of the various ethnic groups so as to optimise the reinforcement of non-smoking attitudes, increase self efficacy towards non-smoking, and to develop refusal skills against pressures to smoke. These data could also provide the impetus for more effective and comprehensive tobacco control policies.

\section{ACKNOWLEDGEMENT}

We acknowledge financial support from the Medical Research Council of South Africa, National Department of Health and UNICEF; technical support from the WHO Tobacco Free Initiative and the Centers for Disease Control and Prevention; support from the National and Provincial Departments of Education; and the principals, staff and students from all participating schools.

\section{Authors' affiliations}

D Swart, P Reddy, National Health Promotion Research and Development Group, Medical Research Council of South Africa, Cape Town, South Africa

R A C Ruiter, Department of Experimental Psychology, Maastricht University, Maastricht, The Netherlands

$\mathbf{H}$ de Vries, Department of Health Education and Promotion, Maastricht University

\section{REFERENCES}

1 Peto R, Lopez AD, Boreham J, et al. Developing populations: the future health effects of current smoking patterns. In: Mortality from smoking in developed countries, 1950-2000. Oxford: Oxford University Press; 1994, A101-3.

2 Peto R, Lopez A, Boreham J, et al. Mortality from tobacco in developed countries: indirect estimation from national vital statistics. Lancet 1992;339: 1268-78. 
3 Center for Disease Control. Cigarette smoking among adults - United States. MMWR Morb Mortal Wkly Rep 1999;48:986-3.

4 US Department of Health and Human Services. Preventing tobacco use among young people. A report of the Surgeon General, 1994. Atlanta, Georgia: Public Health Service, Centers for Disease Control and Prevention, Office on Smoking and Health, 1994. (US Government Printing Office Publication No S/N 017-001-00491-0.)

5 Swart D, Reddy P, Pitt B, et al. The prevalence and determinants of tobacco use among grade 8-10 learners in South Africa. A global youth school-based survey. Cape Town: Medical Research Council (SA); 2001

6 Center for Disease Control. Tobacco use among high school students United States.MMWR Morb Mortal Wkly Rep 1998;47:229-33.

7 Hill D, White V, Segan K. Cigarette smoking in secondary school students in 1993. Austr J Public Health 1995:19:445-9.

8 Gillespie A, Stanton W, Lowe JB, et al. Feasibility of school-based smoking cessation programs. J School Health 1995;65:432-7.

9 Dappen A, Swartz RH, O'Donnell R. A survey of adolescent smoking patterns. J Am Board Family Pract 1996;9:7-13.

10 WHO/TFI talk. Statement for treatment of tobacco dependence. 1999 April 4 [cited 1999 December].URL: http://www.globalink.org/gt/ mailing_lists/archive/nb-ffi/latest/msg00001.html

11 Reddy P, Meyer-Weitz A, Yach D. Smoking status, knowledge of health effects and attitudes towards tobacco control in South Africa. South African Med J 1996;86:1389-93.

12 Reddy P, Meyer-Weitz A, Levine J. Smoking prevalence among adult smokers in South Africa. Cape Town: National Health Promotion Research and Development Office, Medical Research Council; 1998 [unpublished report.]

13 Meyer-Weitz A, Reddy P, Levine J. A comparison of the effects of South Africa's first tobacco control legislation on adult South African's smoking status, their knowledge of smoking related diseases and perceptions regarding the legislation: February 1995-October 1996. Cape Town: Medical Research Council (SA); 1998.

14 Department of Health and Medical Research Council. South Africa Demographic and Health Survey 1998. Preliminary Report; 1998.

15 Guthrie T, Shung-King M, Steyn K, et al. Children and tobacco in Southern Africa. A literature review of health effects, youth smoking patterns and tobacco control measures. Cape Town: The Child Health Policy Institute, Department of Paediatrics and Child Health, University of Cape Town. The Chronic Diseases of Lifestyle Programme, Medical Research Council, 2000

16 Tobacco Products Amendment Act, 1999. Act no. 12, 1999 Government Gazette. Vol 406, No. 19962, Cape Town, 23 April 1999.

17 Tobacco Products Amendment Act, 1999 Regulations. Government Gazette. Regulation Gazette No. 6689. Vol. 414, No. 20687. Pretoria, 3 December 1999.

18 Centers for Disease Control. Draft Global Youth Tobacco Survey (GYTS) 1999 handbook (class selection). Atlanta; CDC, 1999.

19 Tabachnick BG, Fidell LS. Using multivariate statistics, 3rd ed. New York: HarperCollins; 1996.

20 Davis RM. Promotion of cigarettes in developing countries. JAMA 1986;255:993.

21 World Bank. Curbing the epidemic. Governments and the economics of tobacco control. Washington; The International Bank for Reconstruction and Development/The World Bank; 1999.

22 Gajalakshmi CK, Jha P, Ranson K, et al. Global Patterns of smoking and smoking-attributable mortality. In: Jha P, Chaloupka F, eds. Tobacco control in developing countries, 1st ed. New York: Oxford University Press; 2000: 11-39.

23 Stead L. Lancaster T. A systematic review of interventions for preventing tobacco sales to minors. Tobacco Control 2000;9:169-76. 